\title{
What is the prevalence of imaging-defined intra-articular hip pathologies in people with and without pain? A systematic review and meta-analysis
}

\author{
Joshua J Heerey, ${ }^{1}$ Joanne L Kemp, ${ }^{1}$ Andrea B Mosler, ${ }^{2}$ Denise M Jones, ${ }^{1}$ Tania Pizzari, \\ Richard B Souza, ${ }^{3}$ Kay M Crossley ${ }^{1}$
}

- Additional material is published online only. To view please visit the journal online (http://dx.doi.org/10.1136/ bjsports-2017-098264).

${ }^{1}$ La Trobe Sport and Exercise Medicine Research Centre, School of Allied Health, College of Science, Health and Engineering, La Trobe University, Melbourne, Victoria, Australia ${ }^{2}$ Rehabilitation Department, Aspetar Orthopaedic and Sports Medicine Hospital, Doha, Qatar ${ }^{3}$ Department of Physical Therapy and Rehabilitation Science, University of California, San Francisco, California, USA

\section{Correspondence to}

Joshua J Heerey, La Trobe Sport and Exercise Medicine Research Centre, School of Allied Health, College of Science, Health and Engineering, La Trobe University, Melbourne, VIC, Australia; j.heerey@latrobe.edu.au

Accepted 30 November 2017 Published Online First 14 March 2018

\section{ABSTRACT \\ Background Intra-articular hip pathologies are thought} to be associated with the development of hip and groin pain. A better understanding of the relationship between symptoms and imaging findings may improve the management of individuals with intra-articular hip pathologies.

Objective To undertake a systematic review and metaanalysis to determine the prevalence of intra-articular hip pathologies in individuals with and without pain.

Methods Seven electronic databases were searched in February 2017 for studies investigating the prevalence of intra-articular hip pathologies using MRI, MRA or CT. Two independent reviewers conducted the search, study selection, quality appraisal and data extraction. Metaanalysis was performed when studies were deemed homogenous, with a strength of evidence assigned to pooled results.

Results In general, studies were moderate to high risk of bias, with only five studies adjudged to be low risk of bias. The 29 studies reporting on the prevalence of intraarticular hip pathologies identified limited evidence of a labral tear prevalence of $62 \%(95 \%$ Cl $47 \%$ to $75 \%)$ in symptomatic individuals, with moderate evidence identifying a labral tear prevalence of $54 \%(95 \% \mathrm{Cl}$ $41 \%$ to $66 \%$ ) in asymptomatic individuals. Limited evidence demonstrated a cartilage defect prevalence of $64 \%(95 \% \mathrm{Cl} 25 \%$ to $91 \%)$ in symptomatic individuals, compared with moderate evidence of a cartilage defect prevalence of $12 \%(95 \% \mathrm{Cl} 7 \%$ to $21 \%)$ in asymptomatic individuals.

Conclusion The prevalence of intra-articular hip pathologies is highly variable in both symptomatic and asymptomatic populations. The prevalence of intra-articular hip pathologies appears to be higher in symptomatic individuals. However, imaging-defined intra-articular hip pathologies are also frequently seen in asymptomatic individuals, highlighting a potential discordant relationship between imaging pathology and pain.

PROSPERO registration number CRD42016035444.

\section{INTRODUCTION}

Hip and groin pain is a common cause of loss of function in young and middle-aged adults. ${ }^{12}$ The prevalence of hip and groin pain is known to be as high as $49 \%$ in athletes and $21 \%$ in population cohorts. $^{13}$ The occurrence of hip and/or groin pain increases with age, ${ }^{3-5}$ and its impact often extends beyond activity reduction, to reduction in participation in work and family activities. ${ }^{16-9}$
Many different structures, sometimes referred to as clinical entities, may contribute to the development of hip and groin pain. ${ }^{10-14}$ Imaging is often used to assist in the diagnosis of intra-articular and extra-articular hip pathology. ${ }^{15-17}$ With the advent of higher-quality imaging, the understanding and implications of commonly seen hip morphology and pathology requires attention. ${ }^{18}$

Surgical management for morphological and articular pathologies has increased dramatically, ${ }^{19}{ }^{20}$ with Montgomery et $a l^{20}$ highlighting a $365 \%$ increase between 2004 and 2009. However, some of the articular pathologies targeted by surgical management may exist within the 'normal spectrum' related to age, gender and activity exposure. This concept is evident in a number of other anatomical regions, including the knee, shoulder and spine. ${ }^{21-25}$ With imaging findings of intra-articular hip pathology in the presence of prolonged symptoms being the catalyst for surgical interventions, ${ }^{2627}$ it seems prudent to explore the relationship of imaging findings and symptoms. Recent reviews have highlighted normal variants of the acetabular labrum, ${ }^{28}$ as well as a high prevalence of labral tears in symptomatic and asymptomatic subjects. ${ }^{29} 30$ However, none of these reviews aimed to report the prevalence of all intra-articular hip pathologies. In addition, a number of relevant studies have been published subsequent to these reviews. Therefore, the aim of this review was to determine the prevalence of intra-articular hip pathologies in symptomatic and asymptomatic individuals irrespective of their sex, age, level of activity and presence or absence of radiographic hip osteoarthritis (OA).

\section{METHODS}

This systematic review was undertaken using the preferred reporting guidelines for systematic reviews and meta-analysis (PRISMA). The review protocol was registered on the PROSPERO international prospective register of systematic reviews (http:// www.crd.york.ac.uk/PROSPERO) on 16 February 2016. Registration number: CRD42016035444.

\section{Eligibility criteria}

Prespecified inclusion criteria were (1) studies written in English language that used cross-sectional, case-control, case series and cohort designs; (2) studies that included participants with and without hip, groin and buttock pain; (3) studies that performed magnetic resonance imaging 
(MRI), magnetic resonance arthrography (MRA) or computed tomography (CT) with or without contrast to investigate the presence of intra-articular pathology; and (4) studies that had a primary outcome to determine the prevalence of intra-articular pathologies (including labral tears, cartilage defects, bone marrow lesions (BML), ligamentum teres tears and herniation pits) or a primary aim to report femoroacetabular impingement (FAI) prevalence and intra-articular pathology prevalence. No restrictions were placed on the age of study participants. Studies were excluded if they (1) reported prevalence of intra-articular pathology, but it was not the primary aim of the study; (2) investigated intra-articular pathology in the following hip conditions: slipped capital femoral epiphysis or Legg-Calve-Perthes disease; (3) used other forms of imaging to determine prevalence including X-ray, isotopic bone scans and ultrasound; (4) determined prevalence by arthroscopy or open surgery; (5) included less than five participants; (6) were systematic reviews, abstracts or unpublished data; and (7) were not published in the English language.

\section{Search strategy}

A systematic search was undertaken using MEDLINE, PubMed, CINAHL, EMBASE, SPORTDiscus, Scopus and Cochrane databases from inception to 19 May 2016; the search was then repeated in its entirety on 27 February 2017. In addition, reference lists of included articles were screened, and citation tracking using Google Scholar was undertaken. The search strategy was independently undertaken by two authors (JJH and DMJ) using database-specific controlled vocabulary and keyword terms. The search strategy for each respective database can be found in online supplementary appendix 1 .

At completion of database searching, all potentially eligible articles were exported into Endnote X7 (Thomson Reuters, Carlsbad, California, USA) and duplicates removed. The specified inclusion/exclusion criteria were independently applied to the yield achieved from database and secondary searching by two authors (JJH, DMJ). Full-text articles were subsequently retrieved and screened independently by each author for eligibility. Final inclusion was determined by each author (JJH, DMJ) independently and then a consensus meeting was held to determine the final list of included articles. If disagreements arose in relation to the study's eligibility, a third reviewer (JLK) was consulted to determine eligibility.

\section{Risk of bias}

Two authors (JJH, DMJ), independently evaluated each eligible study for risk of bias using a tool designed for prevalence papers. ${ }^{31}$ This tool consists of 10 'yes' or 'no' questions that evaluate both external (four questions) and internal validity (six questions) (table 4), a 'yes' is associated with low risk of bias (LR) and a 'no' with high risk of bias (HR). An article that fails to report sufficient detail to enable scoring for an item is given a 'no' which equates to HR. ${ }^{31}$ Modification was made to question seven which evaluated the reliability of the imaging modality, with an intraclass correlation coefficient $>0.40$ and Cohen's kappa (к) $>40 \%$ considered to be LR. At the completion of scoring, each article receives an overall risk of bias score based on the number of items that demonstrate HR. The articles were then grouped into LR (0-3 items), moderate risk (MR) (4-5 items) and HR ( $\geq 6$ items) derived from literature using the same tool for risk of bias appraisal..$^{32}$ If disagreements arose in relation to a study's risk of bias, a third independent reviewer (JLK) resolved the discrepancy. Inter-rater reliability was evaluated with $\mathrm{K}$, with values $>80 \%$ considered excellent agreement, between $60 \%$ and $80 \%$ substantial agreement, $40 \%$ and $60 \%$ moderate agreement and $<40 \%$ poor to fair agreement. ${ }^{33}$

\section{Data extraction}

Data from all 29 articles were independently extracted by two authors (JJH, $\mathrm{ABM})$. Consensus meetings were held following data extraction of the first 10 articles, and after the completion of the 29 articles, to discuss discrepancies in extraction and to reach consensus. A third author (KMC) was used to reach consensus if discrepancies in data extraction occurred between the two authors. If additional data were required, the corresponding authors were contacted. Where two articles reported the same data set, the studies were examined for discrepancies and the author was contacted if required to seek clarity. The extracted data included author, study design, number of study participants (and hips), demographics, imaging modality and study findings (intra-articular pathology) (tables 1-3).

\section{Data synthesis and analysis}

In relation to this systematic review, as none of the included studies investigated community-based populations, the term prevalence was used to define the frequency of intra-articular pathologies in each study's included population. The prevalence of intra-articular hip pathology was determined by dividing the number of cases by the total number of participants in the specified population. Comprehensive Meta-Analysis Software (V.3.0, Biostat, USA) was used to determine prevalence and $95 \%$ CIs. Prevalence was presented at a per person level, and if the study did not present sufficient information to enable per person analysis, prevalence was reported per hip (if the request for per person data was not successful). In the event that a study used two or more radiologists to evaluate the presence of intra-articular pathologies, an average prevalence score was determined for each of the pathologies reported. Additional intra-articular hip pathologies that were only reported in one symptomatic and asymptomatic study were displayed in supplementary content. Pooled data were presented in per person format, with per hip analysis summarised in text, and details presented in the supplementary content.

Primary subgroup analysis occurred on the presence or absence of pain. Secondary group analysis was completed on the basis of the method used to report prevalence (per person or per hip) and imaging modality (MRI, MRA or CT).

Pathology was recorded as present or absent, due to the variation in assessment, and grading of pathology in the included studies. In relation to cartilage defects, only studies that reported femoral and acetabular defects together were considered for primary analysis. Where studies reported femoral and acetabular defects independently, qualitative analysis was undertaken.

Meta-analyses were undertaken only with studies adjudged to be LR and MR using a random effects model. High risk of bias studies were not included in meta-analyses in line with recent recommendations. ${ }^{34}{ }^{35}$ Qualitative analyses were undertaken when pooling of data was precluded because of clinical heterogeneity or if adjudged to be HR. The level of statistical heterogeneity for the pooled data was evaluated with $\mathrm{Q}$ and $\mathrm{I}^{2}$ statistics. ${ }^{34}$ An $I^{2} \leq 25 \%$ represented low levels of statistical heterogeneity, $25 \%-\leq 50 \%$ moderate and $\geq 75 \%$ high heterogeneity. ${ }^{36}$ Sensitivity analysis was undertaken first with removal of studies using a MRI field strength $<1.5$ tesla $(\mathrm{T})$ and second in only studies using 3 T MRI. 


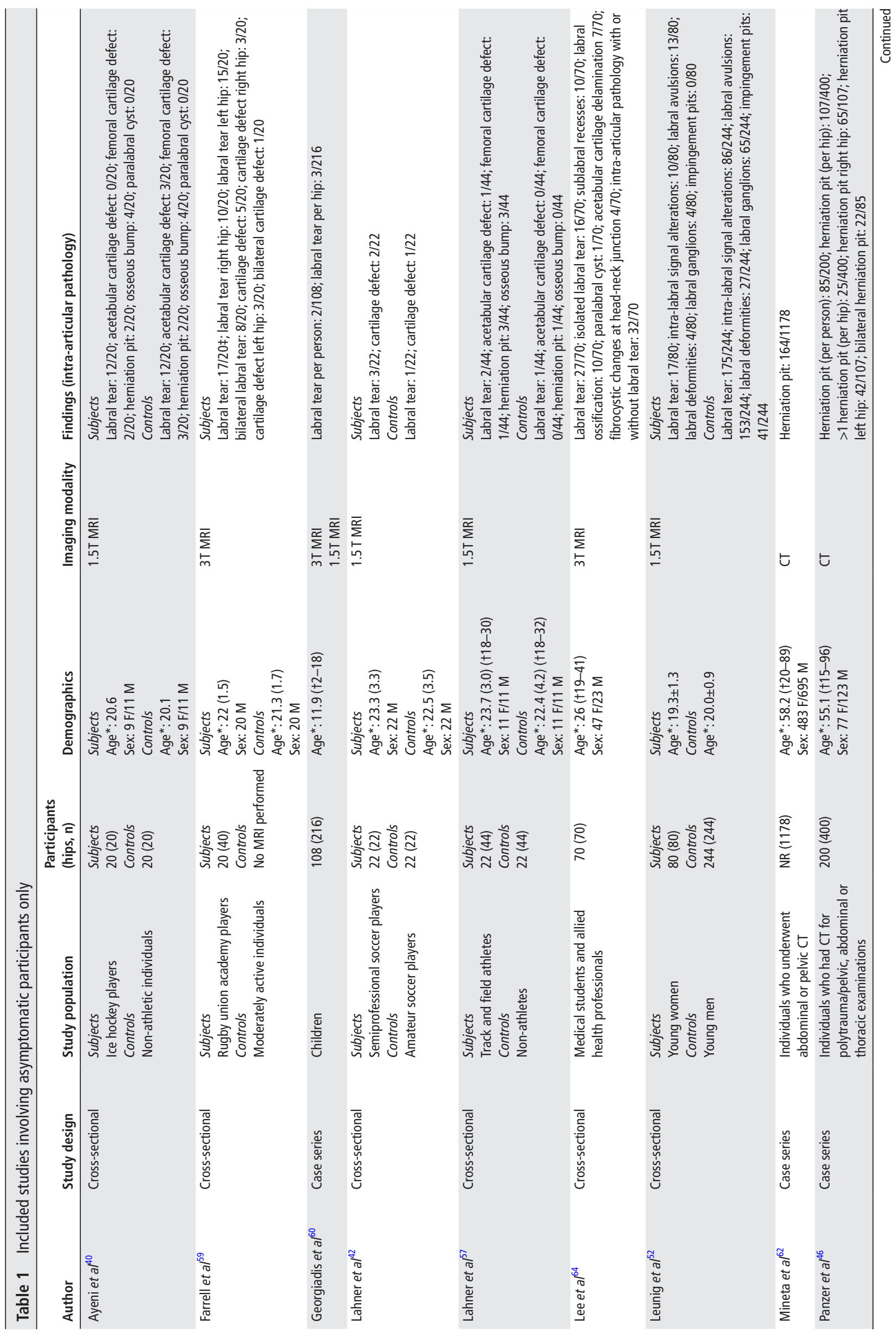




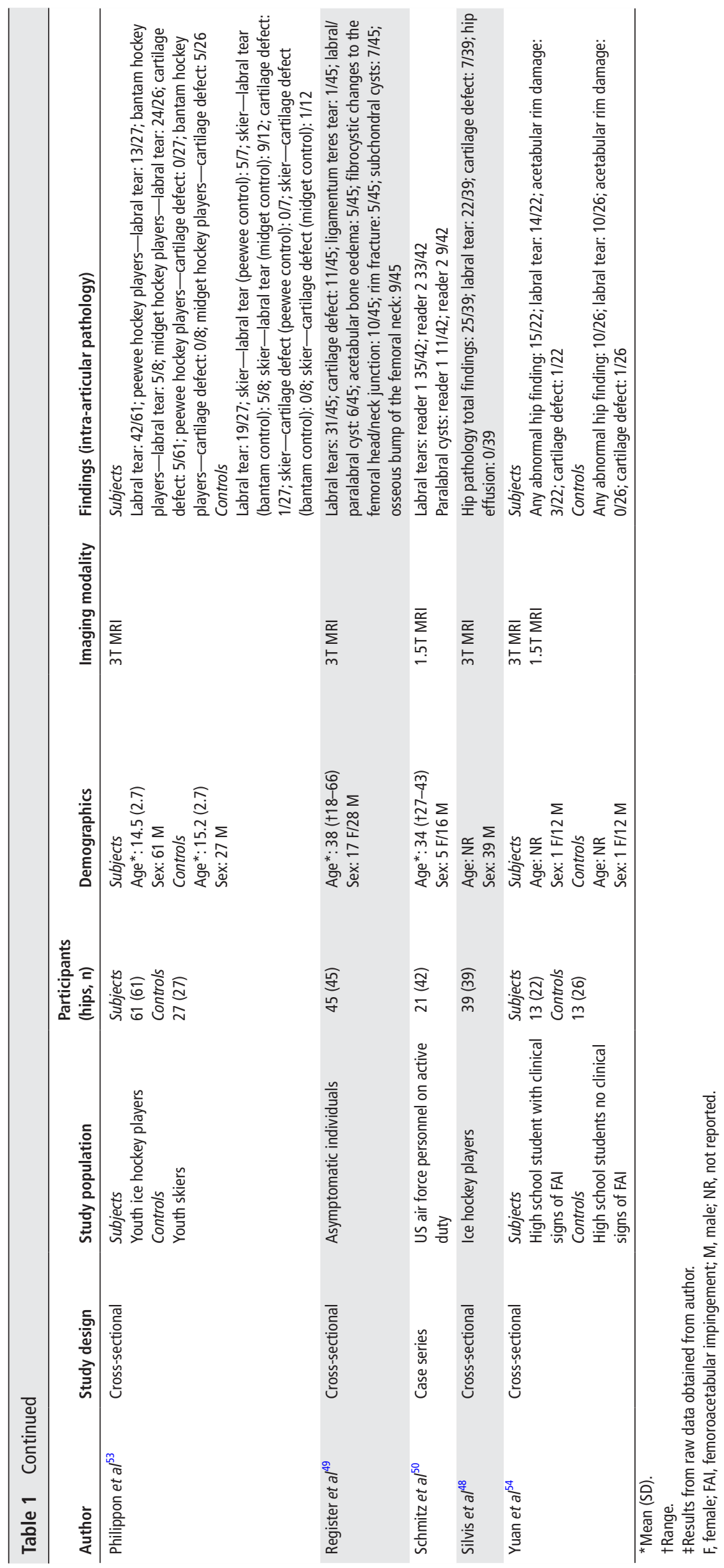

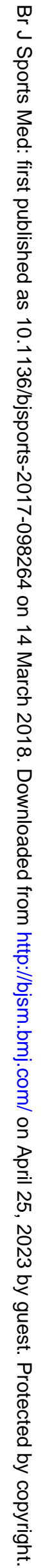


Table 2 Included studies involving symptomatic participants only

\begin{tabular}{|c|c|c|c|c|c|c|}
\hline Author & Study design & Study population & $\begin{array}{l}\text { Participants } \\
\text { (hips, n) }\end{array}$ & Demographics & $\begin{array}{l}\text { Imaging } \\
\text { modality }\end{array}$ & Findings (intra-articular pathology) \\
\hline $\begin{array}{l}\text { Domb } \\
\text { et }\left.a\right|^{55}\end{array}$ & Case series & $\begin{array}{l}\text { Retired NFL players } \\
\text { with hip pain }\end{array}$ & $38(62)$ & $\begin{array}{l}\text { Age*: }^{*} 3(+27-39) \\
\text { Sex: } 38 \mathrm{M}\end{array}$ & $\begin{array}{l}1.5 \mathrm{~T} \mathrm{MRI} \\
1.5 \mathrm{~T} \mathrm{MRA}\end{array}$ & $\begin{array}{l}\text { Labral tear: 55/62; cartilage defect (gr 1/2): 61/62; cartilage defect } \\
\text { (gr 3): 0/62; ligamentum teres tear (partial to severe): 50/62; } \\
\text { osteophyte: 3/62; subchondral bone cyst: } 9 / 62 ; \text { paralabral cyst: 3/62; } \\
\text { bursitis: 0/62; loose bodies: 0/62; transverse ligament tear: 2/62; } \\
\text { AVN: } 0 / 62\end{array}$ \\
\hline $\begin{array}{l}\text { Jayakar } \\
\text { et a }\left.\right|^{61}\end{array}$ & Case series & $\begin{array}{l}\text { Individuals with } \\
\text { hip pain }\end{array}$ & $192(208)$ & $\begin{array}{l}\text { Age }^{*}: 61(8.9) \\
(+50-92) \\
\text { Sex: } 139 \mathrm{~F} / 69 \mathrm{M}\end{array}$ & MRA & $\begin{array}{l}\text { Labral tear: } 152 / 208 \text {; labral fraying: 42/208; no labral tearing: } \\
\text { 14/208; tonnis gr } 0-1 \text { - labral tearing: } 133 / 182 \text {, labral fraying: } \\
\text { 35/182, no labral tearing: } 14 / 182 \text {; tonnis gr } 2-3 \text {-labral tearing: } \\
\text { 19/26, labral fraying: } 7 / 26 \text {, no labral tearing: } 0 / 26\end{array}$ \\
\hline $\begin{array}{l}\text { Kassarjian } \\
\text { et } a^{41}\end{array}$ & Case series & $\begin{array}{l}\text { Individuals with } \\
\text { clinical signs of FAI }\end{array}$ & $40(42)$ & $\begin{array}{l}\text { Age }^{*}: 36.5(12) \\
(+17-67) \\
\text { Sex: } 18 F / 22 M\end{array}$ & 1.5T MRA & $\begin{array}{l}\text { Labral tear: } 42 / 42 \text {; cartilage defect: } 40 / 42 \text {; triad (abnormal AA, } \\
\text { anterosuperior cartilage abnormalities, anterosuperior labral tear): } \\
\text { 37/42; paralabral cyst: } 6 / 42 \text { ( } 6 / 6 \text { triad abnormalities); herniation } \\
\text { pit: } 2 / 42 \text { (2/2 triad abnormalities); os acetabuli: } 17 / 42 \text { (16/17 triad } \\
\text { abnormalities) }\end{array}$ \\
\hline $\begin{array}{l}\text { Narvani } \\
\text { et } a^{44}\end{array}$ & Case series & $\begin{array}{l}\text { Individuals playing } \\
\text { sport with groin } \\
\text { pain }\end{array}$ & $18(18)$ & $\begin{array}{l}\text { Age*: } 30.5(8.5) \\
(17-48) \\
\text { Sex: } 5 \text { F/13 M }\end{array}$ & 1T MRA & Labral tear: $4 / 18$ \\
\hline $\begin{array}{l}\text { Neiman } \\
\text { et al }\end{array}$ & Case series & $\begin{array}{l}\text { Individuals with } \\
\text { hip pain }\end{array}$ & 229 (229) & $\begin{array}{l}\text { Age* }^{*} 36.5(14.2) \\
(+18-67) \\
\text { Sex: } 102 \mathrm{~F} / 127 \mathrm{M}\end{array}$ & 1.5T MRA & $\begin{array}{l}\text { Labral tear: } 146 / 229 \text {; cartilage defect: } 64 / 229 \text {; ligamentum teres } \\
\text { partial tears: } 2 / 229 \text {; ligamentum teres complete tears: } 2 / 229 \text {; } \\
\text { synovitis: } 3 / 229 \text {; transient osteoporosis of the hip: } 2 / 229 \text {; PVN: } \\
1 / 229 ; \text { AVN: } 1 / 229\end{array}$ \\
\hline $\begin{array}{l}\text { Neumann } \\
\text { et a }\left.\right|^{45}\end{array}$ & Case series & $\begin{array}{l}\text { Individuals with } \\
\text { mechanical hip pain }\end{array}$ & $100(100)$ & $\begin{array}{l}\text { Age }^{*}: 39(13) \\
(+17-76) \\
\text { Sex: } 76 \mathrm{~F} / 24 \mathrm{M}\end{array}$ & 1.5T MRA & $\begin{array}{l}\text { Labral tear: } 66 / 100 ; \text { cartilage defect: } 76 / 100 ; \text { BML: } 29 / 100 ; \\
\text { osteophytes: } 32 / 100 \text {; subchondral cysts: } 23 / 100 ; \text { subchondral } \\
\text { sclerosis: } 22 / 100\end{array}$ \\
\hline $\begin{array}{l}\text { Pizzolatti } \\
\text { et } a l^{47}\end{array}$ & Case series & $\begin{array}{l}\text { Individuals with } \\
\text { suspicion of labral } \\
\text { tear }\end{array}$ & $96(108)$ & $\begin{array}{l}\text { Age* }^{*} \text { M } 39.3 \\
(+18-63) \\
\text { Age* }^{*} \mathrm{~F} 41.3 \\
(+20-73) \\
\text { Sex: } 59 \mathrm{~F} / 37 \mathrm{M}\end{array}$ & $\begin{array}{l}\text { 0.5T MRA } \\
\text { 1.5T MRA }\end{array}$ & $\begin{array}{l}\text { Labral tear (per person): } 96 / 96 \text {; labral tear (per hip): } 108 / 108 ; \\
\text { isolated labral tears: } 24 / 108 ; \text { completely torn labrum: } 43 / 108 \text { hips; } \\
\text { first-degree labral tear: } 44 / 108 \text {; second-degree labral tear: } 34 / 108 ; \\
\text { third-degree labral tear: } 30 / 108 ; \text { cartilage defect: } 88 / 108 ; \text { cartilage } \\
\text { defect in entire weightbearing zone: } 46 / 108 ; \text { first-degree cartilage } \\
\text { defect: } 55 / 108 \text {; second-degree cartilage defect: } 14 / 108 ; \text { third-degree } \\
\text { cartilage defect: } 19 / 108\end{array}$ \\
\hline
\end{tabular}

${ }^{*}$ Mean (SD).

tRange.

AA, alpha angle; AVN, avascular necrosis; BML, bone marrow lesion; F, female; FAI, femoroacetabular impingement; Gr, grade; M, male; MRA, magnetic resonance arthrography;

PVNS, pigmented villonodular synovitis.

The strength of evidence for the pooled results of this review is based on the original methods advocated by van Tulder et $a l^{37}$ and later adapted by Rathleff et al. ${ }^{38}$

Strong evidence: pooled results derived from three or more studies, including a minimum of two LR studies, which are statistically homogenous $(\mathrm{P}>0.05)$.

Moderate evidence: pooled results derived from multiple studies, including at least one LR study, which are statistically heterogeneous $(\mathrm{P}<0.05)$; or from multiple MR and HR studies which are statistically homogenous $(\mathrm{P}>0.05)$.

Limited evidence: pooled results from multiple $\mathrm{HR}$ or MR studies which are statistically heterogeneous $(\mathrm{P}<0.05)$.

\section{RESULTS}

\section{Search results}

The review used the PRISMA flow diagram (figure 1). ${ }^{39}$ In total, 343 citations were identified through the search strategy. At the completion of duplicate removal, 124 citations were screened based on title and abstract. The full-text versions of 56 articles were retrieved and subsequently assessed for eligibility using the inclusion criteria. Four ${ }^{40-43}$ additional articles were added after the screening of reference lists and citation tracking. Thirty-one articles were subsequently excluded (online supplementary appendix 2), and the remaining 29 articles $^{40-68}$ were included for data analysis (tables 1-3).

\section{Risk of bias within studies}

The two reviewers agreed on risk of bias items on $96 \%$ of occasions (278/290 items), with a $\mathrm{k}$ value of 0.84 (95\% CI 0.78 to 0.90$)$ representing excellent agreement. ${ }^{33}$ Five of the $29(17 \%)$ included articles were adjudged to be of HR, with 19 of MR and 5 of LR. All 29 studies had HR for items 1 and 2, which highlights the disparity of the included study populations compared with a general population and the inadequacies of the sampling frames used within the studies. In addition, inability to demonstrate the reliability of the assessment method used to determine the prevalence of intra-articular pathology, the use of different imaging methods within the one study population and the reporting of prevalence per hip instead of per person were other notable sources of bias (table 4).

\section{Study characteristics}

The 29 included studies reported prevalence characteristics on 2573 participants and 4410 hips. Fourteen studies (1069 participants, 2662 hips) included only asymptomatic participants, with 10 of the studies reporting a mean age of $<40$ years of age (table 1). ${ }^{40424648-5052-545759606264}$ Eight studies investigating symptomatic participants used MRA to evaluate the prevalence of intra-articular pathology, with seven studies reporting a mean age of $<40$ years of age (tables 2 and 3). ${ }^{4144454755616366}$ Fifteen studies investigated 


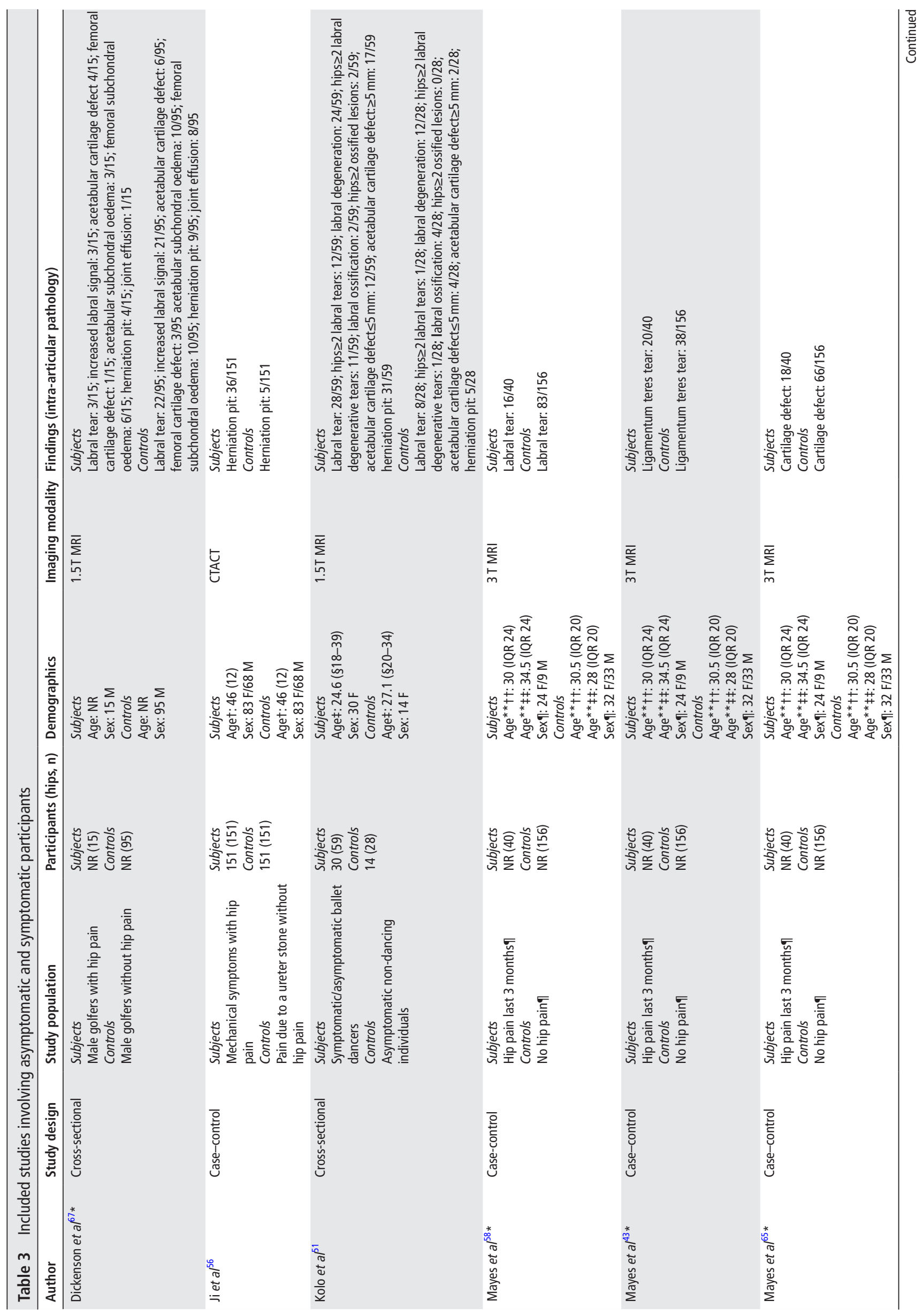




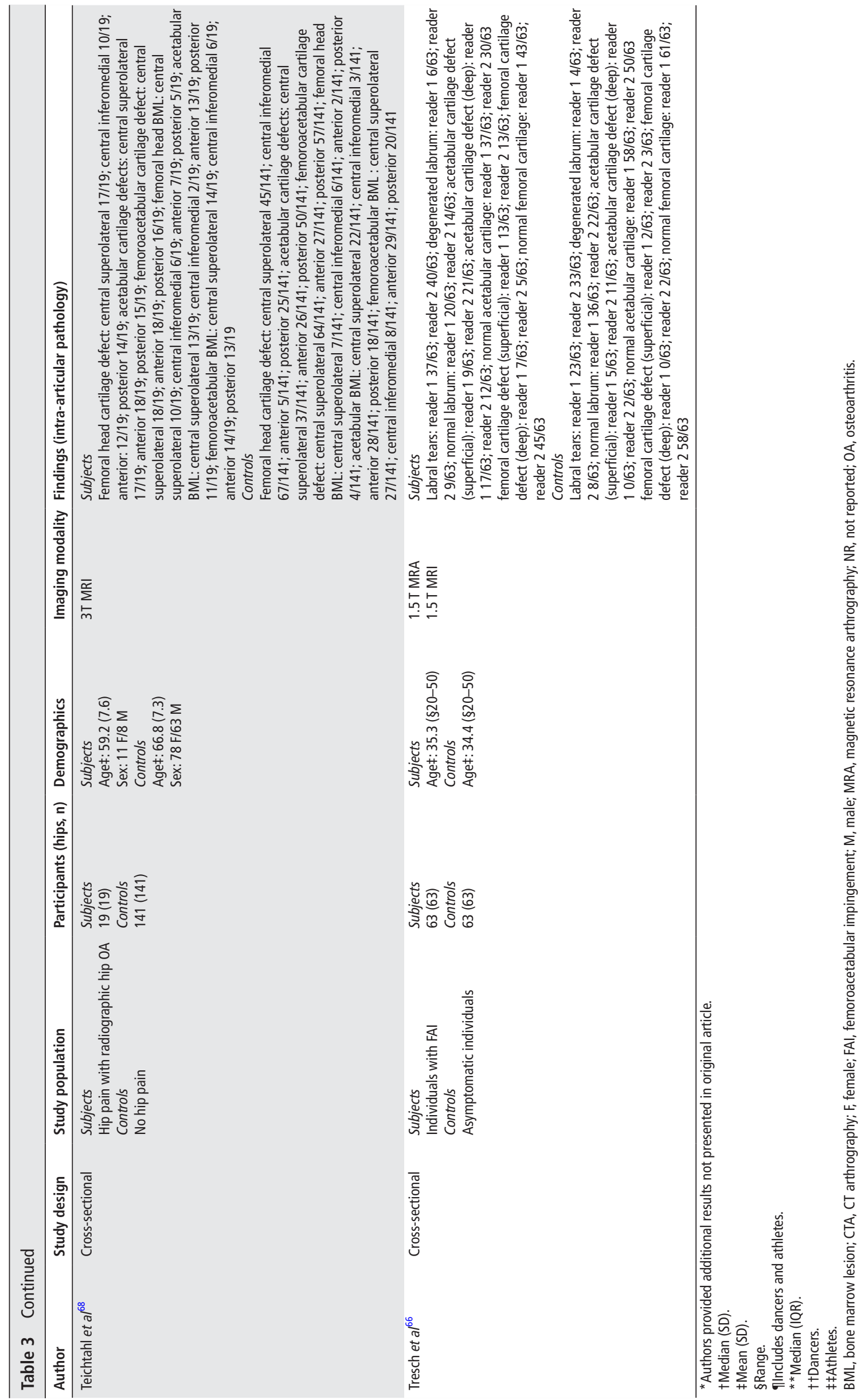




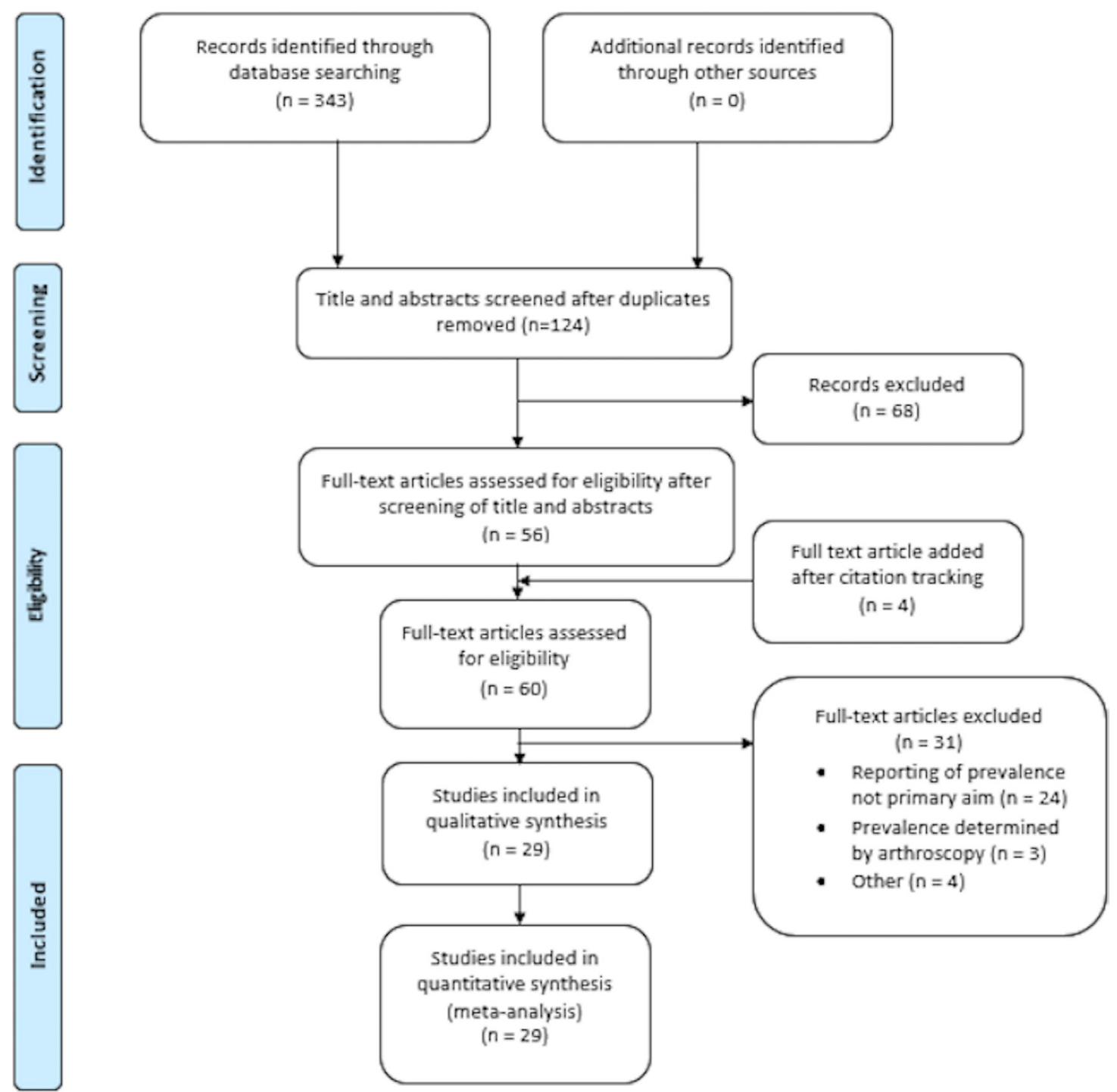

Figure 1 Preferred reporting guidelines for systematic reviews and meta-analysis flow diagram of search results and study selection.

athletic participants, ${ }^{40} 42-44485153-5557-59646567$ with the remaining studies investigating non-athletic participants or not reporting participant activity level. Two studies ${ }^{61} 68$ included participants with radiographic hip OA, with 25 of the remaining 27 studies not identifying if participants had radiographically confirmed hip $\mathrm{OA}^{40-53}$ 55-60 63-67 (online supplementary appendix 3 tables 2-4). Magnetic resonance imaging was used in 20 studies. 404243 48-55 57-60 64-68 Three studies ${ }^{465662}$ evaluated prevalence with CT (one of the three studies $^{56}$ used a case-control design and CT arthrography (CTA) in a symptomatic group). The MRI field strength used in the included studies varied between 0.5 to $3.0 \mathrm{~T}$, with one study ${ }^{61}$ using MRA not reporting the field strength used.

\section{Heterogeneity of included studies}

Heterogeneity ranged between $46 \%-83 \%$ and $87 \%-93 \%$ in pooled studies investigating the prevalence of labral tears in symptomatic and asymptomatic participants, respectively. In the studies investigating symptomatic participants with cartilage defects, high levels of heterogeneity were observed (98\%).
In studies investigating asymptomatic participants, moderate (62\%) to high levels (76\%) were observed.

\section{Prevalence of labral tears}

Twenty-three studies (1911 participants, 2370 hips) reported the prevalence of labral tears. ${ }^{40-42} 444547-55$ 57-61 63646667 Eleven studies reported prevalence per person, 4042444548495253636466 whereas six studies 505155576167 reported prevalence per hip. Six studies ${ }^{41475458-60}$ reported prevalence per person and per hip.

\section{Symptomatic participants}

There was limited evidence of a pooled labral tear prevalence of 62\% (95\% CI 47\% to 75\%) per person from five studies (five MR) 4445476366 using MRA (figure 2). Six studies (one HR, four MR and one LR) ${ }^{415155586167}$ reported prevalence of labral tears per hip in symptomatic participants. There was limited evidence of a pooled labral tear prevalence of $92 \%$ (95\% CI 29\% to 100\%) per hip from two (two MR) ${ }^{41} 61$ MRA studies, with moderate evidence of a pooled labral tear prevalence of $32 \%$ (95\% CI $16 \%$ 
Table 4 Included studies risk of bias

\begin{tabular}{|c|c|c|c|c|c|c|c|c|c|c|c|}
\hline \multirow[b]{2}{*}{ Author } & Item 1 & Item 2 & Item 3 & Item 4 & Item 5 & Item 6 & Item 7 & Item 8 & Item 9 & Item 10 & \multirow{2}{*}{$\begin{array}{l}\text { Overall risk } \\
\text { of bias }\end{array}$} \\
\hline & \multicolumn{4}{|c|}{ External validity } & \multicolumn{6}{|c|}{ Internal validity } & \\
\hline Ayeni et $a l^{40}$ & $\mathrm{HR}$ & HR & $\mathrm{HR}$ & LR & LR & HR & $\mathrm{HR}$ & LR & LR & LR & MR \\
\hline Dickenson et a ${ }^{67}$ & $\mathrm{HR}$ & HR & $\mathrm{HR}$ & LR & LR & HR & LR & LR & LR & HR & MR \\
\hline Domb et $a^{55}$ & $\mathrm{HR}$ & $H R$ & $\mathrm{HR}$ & LR & LR & $\mathrm{LR}$ & $H R$ & $H R$ & LR & $\mathrm{HR}$ & $H R$ \\
\hline Farrell et $a^{59}$ & $\mathrm{HR}$ & HR & $\mathrm{HR}$ & LR & LR & HR & $H R$ & $L R$ & LR & LR & $\mathrm{MR}$ \\
\hline Georgiadis et $a l^{60}$ & $\mathrm{HR}$ & HR & $\mathrm{HR}$ & LR & LR & HR & $\mathrm{HR}$ & HR & LR & LR & $\mathrm{HR}$ \\
\hline Kassarjian et a ${ }^{41}$ & $\mathrm{HR}$ & HR & $\mathrm{HR}$ & LR & LR & $L R$ & $\mathrm{HR}$ & $L R$ & LR & $\mathrm{HR}$ & MR \\
\hline Kolo et $\left.a\right|^{51}$ & $\mathrm{HR}$ & HR & HR & LR & LR & LR & HR & LR & LR & HR & MR \\
\hline Lahner et al/2 & $\mathrm{HR}$ & HR & HR & LR & LR & HR & HR & LR & LR & LR & MR \\
\hline Lahner et $a F^{57}$ & $\mathrm{HR}$ & HR & $\mathrm{HR}$ & LR & LR & HR & HR & LR & LR & HR & $\mathrm{HR}$ \\
\hline Lee et $a l^{64}$ & $\mathrm{HR}$ & HR & $\mathrm{HR}$ & LR & LR & LR & LR & $L R$ & LR & LR & LR \\
\hline Mineta et $a^{/ 62}$ & $\mathrm{HR}$ & $\mathrm{HR}$ & $\mathrm{HR}$ & LR & LR & LR & LR & LR & LR & HR & MR \\
\hline Narvani et $a l^{44}$ & HR & HR & $\mathrm{HR}$ & LR & LR & HR & HR & LR & LR & LR & MR \\
\hline Neiman et $a^{63}$ & $\mathrm{HR}$ & HR & $\mathrm{HR}$ & LR & LR & HR & HR & LR & LR & LR & MR \\
\hline Neumann et $a l^{45}$ & $\mathrm{HR}$ & HR & $\mathrm{HR}$ & LR & LR & LR & HR & LR & LR & LR & MR \\
\hline Panzer et a $\left.\right|^{46}$ & HR & HR & $\mathrm{HR}$ & LR & LR & LR & LR & HR & LR & LR & MR \\
\hline Philippon et $\left.a\right|^{53}$ & $\mathrm{HR}$ & $H R$ & $\mathrm{HR}$ & LR & LR & HR & $H R$ & $L R$ & LR & LR & MR \\
\hline Pizzolatti et a ${ }^{47}$ & $\mathrm{HR}$ & HR & $\mathrm{HR}$ & LR & LR & LR & HR & HR & LR & LR & MR \\
\hline Register et al ${ }^{49}$ & $\mathrm{HR}$ & $H R$ & $\mathrm{HR}$ & LR & LR & $H R$ & $H R$ & $L R$ & LR & LR & MR \\
\hline Schmitz et $a^{50}$ & $\mathrm{HR}$ & HR & $\mathrm{HR}$ & LR & LR & LR & LR & LR & LR & HR & MR \\
\hline Silvis et $a{ }^{48}$ & $\mathrm{HR}$ & HR & $\mathrm{HR}$ & HR & LR & HR & HR & LR & LR & LR & $\mathrm{HR}$ \\
\hline
\end{tabular}

Risk of bias items.

1.Was the study's target population a close representation of the national population in relation to relevant variables, for example, age, sex, occupation?

2. Was the sample frame a true or close representation of the target population?

3. Was some form of random selection used to select the sample, or, was a census taken?

4. Was the likelihood of non-response bias minimal?

5. Were data collected directly from the subjects (as opposed to a proxy)?

6. Was an acceptable case definition used in the study?

7. Was the study instrument that measured the parameter of interest (eg, prevalence of low back pain) shown to have reliability and validity (if necessary)?

8. Was the same mode of data collection used for all subjects?

9. Was the length of the shortest prevalence period for the parameter of interest appropriate?

10. Were the numerator(s) and denominator(s) for the parameter of interest appropriate?

$\mathrm{HR}$, high risk of bias; LR, low risk of bias; MR, moderate risk of bias.

to $54 \%$ ) from two (one MR and one LR) ${ }^{58} 67$ studies using MRI (online supplementary appendix 3 figure 1). The remaining two studies (one $\mathrm{HR}$ and one $\mathrm{MR}$ ) reported a labral tear prevalence of $89 \%^{55}$ and $48 \%^{51}$ per hip, respectively.

\section{Asymptomatic participants}

There was moderate evidence of a pooled labral tear prevalence of 54\% (95\% CI $41 \%$ to $66 \%$ ) per person from eight studies (six MR and two LR) 4042495253596466 using MRI (figure 2). Three studies (three HR) ${ }^{48} 5460$ not included in the meta-analysis reported a labral tear prevalence per person in children of $1.9 \%,{ }^{60}$ high school athletes $(85 \%)^{54}$ and ice hockey players $(56 \%){ }^{48}$

Six studies (two HR, three MR and one LR) 505154575867 reported prevalence of labral tears per hip in asymptomatic participants. Moderate evidence from four studies (three MR and one LR) using MRI demonstrated a pooled prevalence of $46 \%$ (95\% CI 24\% to 70\%) per hip (online supplementary appendix 3 figure 1). The remaining two studies (two $\mathrm{HR})^{54} 57$ reported a labral tear prevalence per hip of $38 \%$ and 3\%, respectively. No studies used MRA in asymptomatic participants.

\section{Sensitivity analysis}

In symptomatic participants, sensitivity analysis demonstrated a pooled labral tear prevalence of $64 \%$ (95\% CI 59\% to 69\%; $\left.\mathrm{Q}=0.3 ; \mathrm{P}=0.861 ; \mathrm{I}^{2}=0 \%\right)$ per person in studies using an MRI field strength of $\geq 1.5 \mathrm{~T}$. Sensitivity analysis was unable to be performed for studies using $3 \mathrm{~T}$ MRI due to an insufficient number of studies. The labral tear prevalence in asymptomatic participants was 56\% (95\% CI 45\% to 67\%; Q $=55.0 ; \mathrm{P}<0.001 ; \mathrm{I}^{2}=84 \%$ ) per person and $34 \%$ (95\% CI $17 \%$ to $57 \%$; $\mathrm{Q}=69.8 ; \mathrm{P}<0.001$; $\left.\mathrm{I}^{2}=93 \%\right)$ per hip when studies using an MRI field strength $<1.5 \mathrm{~T}$ 


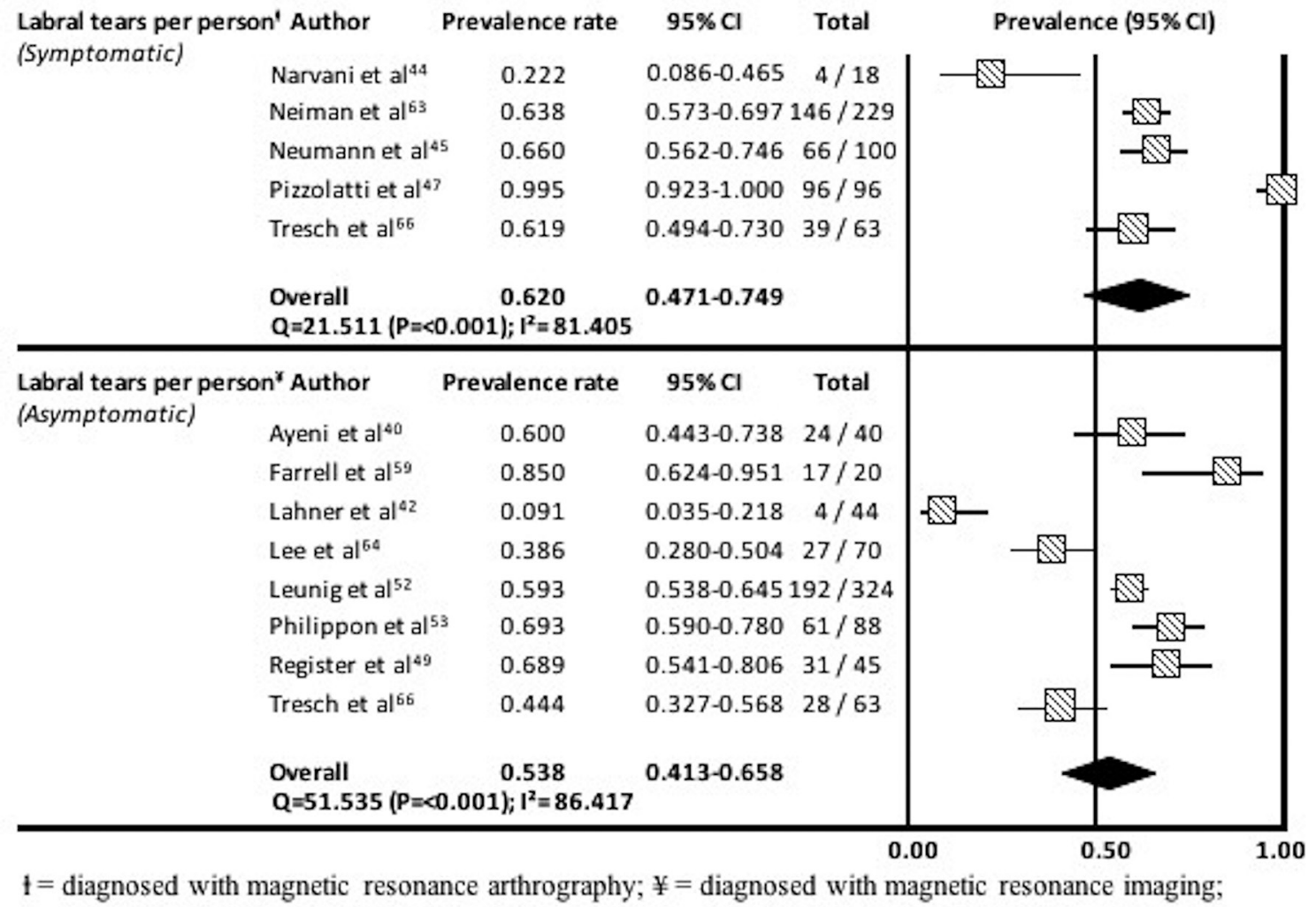

Figure 2 Prevalence and $95 \%$ Cls of labral tears in symptomatic and asymptomatic participants among studies that reported prevalence per person.

were removed. In studies only using $3 \mathrm{~T}$ MRI in asymptomatic individuals, the labral tear prevalence was $63 \%$ (95\% CI $47 \%$ to $\left.76 \% ; \mathrm{Q}=21.9 ; \mathrm{P}=<0.001 ; \mathrm{I}^{2}=82 \%\right)$ per person, with analysis not undertaken at per hip level due to an insufficient number of studies.

\section{Prevalence of cartilage defects}

Nineteen studies (1402 participants, 1722 hips) reported the prevalence of cartilage defects. ${ }^{40-42} 45$ 47-49 51 53-55 5759 63-68 Twelve studies analysed prevalence per person $4042454849535963-6668$ and four studies reported prevalence per hip. ${ }^{5155} 5767$ Three studies reported prevalence using per person and per hip analysis. 414754

\section{Symptomatic participants}

There was limited evidence of a pooled cartilage defect prevalence of $64 \%$ (95\% CI 25\% to 90\%) per person from three studies (three MR) ${ }^{45} 4763$ that used MRA (figure 3). Two studies (two MR) ${ }^{66} 68$ reported acetabular and femoral cartilage defects independently. One study ${ }^{68}$ reported femoral (53\%-90\%) and acetabular (79\%-95\%) defects in specified hip joint regions. The remaining study ${ }^{66}$ reported acetabular (23\% and 24\%) and femoral cartilage (10\% and $21 \%)$ defect prevalence.

Five studies reported prevalence per hip. ${ }^{4154555867}$ One study $(\mathrm{MR})^{41}$ reported a cartilage defect prevalence of $95 \%$ in participants with FAI. Three (one HR, one MR and one LR) of the remaining four studies used a combination of MRI and MRA $(98 \%)^{55}$ and MRI in isolation (45\% and 49\%) $)^{5158}$ to identify cartilage defects. The final study $(\mathrm{MR})^{67}$ reported on acetabular $(27 \%)$ and femoral cartilage defects $(7 \%)$ in golfers with hip pain.
Asymptomatic participants

There was moderate evidence of a pooled cartilage defect prevalence of $12 \%$ (95\% CI $7 \%$ to 21\%) per person, from five studies (one LR and four MR) 4249535964 using MRI (figure 3). Two studies (two HR) ${ }^{48} 54$ reported cartilage defect prevalence per person in ice hockey players $(18 \%)^{48}$ and high school athletes (8\%). ${ }^{54}$ Moderate evidence of a pooled cartilage defect prevalence of $33 \%$ (95\% CI 16\% to 56\%) per hip was demonstrated from two studies (one MR and one LR) ${ }^{51}{ }^{65}$ using MRI (online supplementary appendix 3 figure 2). One study (HR) ${ }^{54}$ reported a cartilage defect prevalence per hip of $4 \%$. Five studies (one HR and four MR) ${ }^{405766-68}$ reported the prevalence of acetabular and femoral cartilage defects independently. Acetabular cartilage defect prevalence was reported per person $(2 \%-35 \%)^{406668}$ and per hip $(1 \%$ and $6 \%),{ }^{5767}$ with femoral cartilage defects identified at per person $(2 \%-48 \%)^{4066} 68$ and per hip level (1\% and $3 \%) .5767$

\section{Sensitivity analysis}

In symptomatic participants, sensitivity analysis demonstrated a pooled cartilage defect prevalence of $52 \%$ (95\% CI $12 \%$ to 90\%; $\left.\mathrm{Q}=57.6 ; \mathrm{P}<0.001 ; \mathrm{I}^{2}=98 \%\right)$ per person. No sensitivity analysis was performed for studies using $3 \mathrm{~T}$ MRI due to an insufficient number of studies. In asymptomatic participants, a cartilage defect prevalence of $13 \%$ (95\% CI $8 \%$ to $20 \%$; $\left.\mathrm{Q}=11.7 ; \mathrm{P}=0.070 ; \mathrm{I}^{2}=49 \%\right)$ per person and $22 \%(95 \% \mathrm{CI} 7 \%$ to $50 \% ; \mathrm{Q}=11.5 \mathrm{P}=0.003 ; \mathrm{I}^{2}=83 \%$ ) per hip was identified in studies using an MRI field strength of $\geq 1.5 \mathrm{~T}$. In studies only using 3 T MRI, a cartilage defect prevalence of 15\% (95\% CI 9\% to $23 \% ; \mathrm{Q}=9.2 ; \mathrm{P}=0.055 ; \mathrm{I}^{2}=57 \%$ ) was demonstrated, with no analysis undertaken at per hip level due to an insufficient number of studies. 


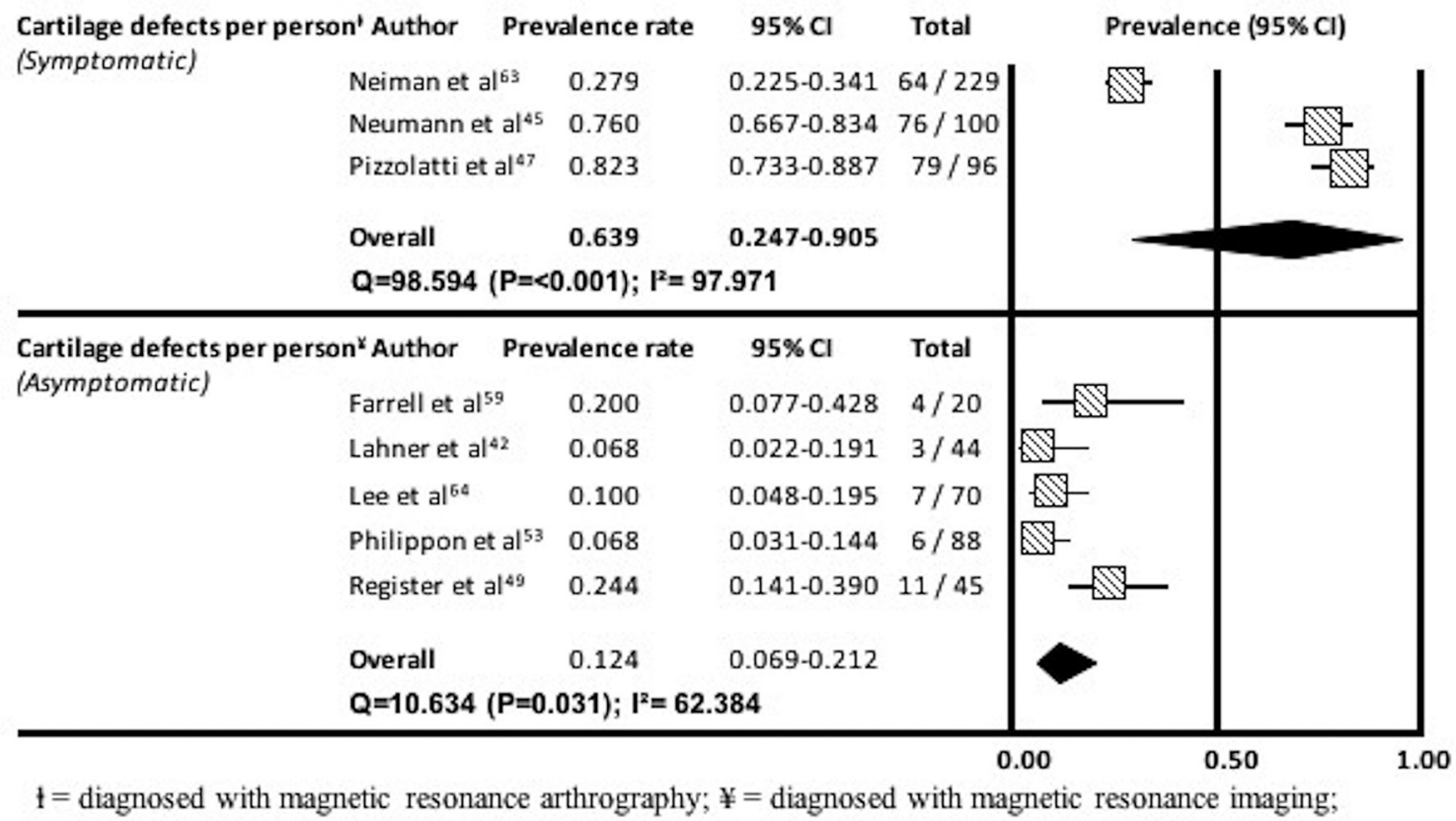

Figure 3 Prevalence and $95 \% \mathrm{Cls}$ of cartilage defects in symptomatic and asymptomatic participants among studies that reported prevalence per person.

\section{Other pathologies \\ Symptomatic participants \\ Bone marrow lesions}

Three studies (three MR) 456768 identified the presence of BML in symptomatic participants. One study ${ }^{45}$ reported a prevalence of $29 \%$, with the remaining two studies ${ }^{67} 68$ evaluating acetabular (11\%-68\%) and femoral (26\%-53\%) lesions independently.

\section{Herniation pits}

Four studies (four MR) ${ }^{41515667}$ reported the prevalence of herniation pits in symptomatic participants. One study ${ }^{56}$ which used CTA reported prevalence per person of 24\%. Two studies ${ }^{51} 67$ evaluated the prevalence of herniation pits per hip using MRI (27\% and 53\%). The final study ${ }^{41}$ identified a prevalence of 5\% in participants with FAI using MRA.

\section{Ligamentum teres tears}

Three studies evaluated the prevalence of ligamentum teres tears. ${ }^{43} 5563$ One study $(\mathrm{MR})^{63}$ reported prevalence per person (2\%). Prevalence was reported per hip (81\% and 50\%) in two studies (one HR and one LR). ${ }^{435}$

\section{Paralabral cysts}

Two studies (one HR and one MR) ${ }^{415}$ reported the prevalence of paralabral cysts per hip (5\% and 14\%).

\section{Asymptomatic participants}

\section{Bone marrow lesions}

Three studies (three MR) 496768 evaluated the presence of BML in asymptomatic participants. One study ${ }^{49}$ reported acetabular lesions only (11\%), with the remaining two studies ${ }^{67} 68$ reporting acetabular (2\%-20\%) and femoral lesions (2\%-11\%) independently.

\section{Herniation pits}

Ten studies (one HR, seven MR and two LR) 4046495152565762 ${ }^{64} 67$ reported the prevalence of herniation pits in asymptomatic participants. Four (two MR and two LR) 40495264 of the six studies reporting prevalence per person used MRI (6\%-22\%). The remaining two studies (two MR) ${ }^{4656}$ used CT (3\% and 43\%). Four studies reported prevalence per hip, three studies (one HR and two MR $)^{515767}$ used MRI (5\%-18\%) and the remaining study (MR) ${ }^{62}$ CT (14\%).

\section{Ligamentum teres tears}

Two studies (one MR and one LR) ${ }^{43}$ reported the prevalence of ligamentum teres tears using MRI. One study $(\mathrm{LR})^{43}$ reported a prevalence per hip of $24 \%$, with the other (MR) ${ }^{49}$ a prevalence per person of $2 \%$.

\section{Paralabral cysts}

Four studies (one LR and three MR) 40495064 identified the prevalence of paralabral cysts in asymptomatic participants. Three studies (one LR and two MR) ${ }^{40} 49$ reported prevalence per person of between $0 \%$ and $13 \%$. One study $(\mathrm{MR})^{50}$ reported a prevalence per hip of $24 \%$.

\section{Other pathologies reported in less than two studies}

Pathologies that were not reported in symptomatic and asymptomatic populations in two or more studies are presented in online supplementary appendix 3 table 1 .

\section{DISCUSSION}

Imaging-defined intra-articular hip pathologies are frequently observed in individuals with and without pain. Diagnostic imaging is now readily used to assist in the evaluation of individuals with hip and groin conditions. ${ }^{10} 17$ However, there is often a poor association between hip symptoms and structural changes seen on imaging. ${ }^{69}$ In total, 29 studies were analysed in this review, with 24 studies adjudged to have moderate to high risk of bias. The external validity of the included studies is generally limited, with no studies investigating large population cohorts. High levels of statistical heterogeneity $\left(\mathrm{I}^{2} \geq 75 \%\right)$ were consistently observed within MRI and MRA studies highlighting that 
considerable variability exists in the prevalence of intra-articular pathologies in the studies included in this review. The results of this review provide a greater understanding of the prevalence of commonly seen hip pathologies in relation to the presence or absence of pain. In summary, labral tears are prevalent in both symptomatic and asymptomatic individuals, although the prevalence is slightly higher in symptomatic groups. Importantly, the prevalence of cartilage defects, BML and ligamentum teres tears was higher in symptomatic than asymptomatic groups.

Labral tears were observed in $62 \%$ of individuals with pain and $54 \%$ of asymptomatic individuals. The high prevalence of labral tears in asymptomatic individuals is a particularly interesting finding, given the reported nociceptive ability of labral tissue $^{70} 71$ and its proposed role in hip joint health. ${ }^{73}$ The questionable relationship between labral pathology and symptoms identified in this review has been mirrored recently in two papers ${ }^{74} 75$ reporting a limited association between labral pathology and self-reported function in a chronic hip pain population and individuals with and without radiographic hip OA. The role that labral tissue plays in the development of symptoms appears more complex than previously thought.

Cartilage defects were evident in $64 \%$ of symptomatic individuals, considerably more than the $12 \%$ of asymptomatic individuals. Thus, it could be considered that cartilage defects might contribute to hip-related symptoms. However, recent work has highlighted a variable relationship between cartilage defects and pain. ${ }^{74-76}$ Moreover, articular cartilage is considered to be aneural under normal physiological conditions. ${ }^{77} 78$ Interestingly, of the included studies that reported acetabular and femoral cartilage defects independently, a trend highlighting a greater prevalence of acetabular cartilage defects was observed in symptomatic individuals. Our finding is consistent with studies reporting associations between acetabular cartilage damage and pain, clinical symptoms and reduction in function. ${ }^{74}$ The presence of cartilage defects could indicate early stages of the arthritic cascade, and the involvement of other tissues such as periarticular tissues, subchondral bone or synovial tissue..$^{7177879}$

This review also highlighted variability in prevalence of herniation pits between those with and without pain. Studies using MRI demonstrated a greater prevalence in symptomatic individuals, conversely studies using CT identified a greater prevalence in asymptomatic individuals. Paralabral cysts were identified similarly in symptomatic and asymptomatic individuals in studies using MRA and MRI, respectively. However, akin to cartilage defects, ligamentum teres tears and BML were seen more often in those with pain. Variability has been observed within literature regarding the nociceptive ability of the ligamentum teres. ${ }^{7180}$ This lack of consensus is reflected in our results, with a quarter of asymptomatic individuals having imaging defined pathology. A greater understanding of the role of ligamentum teres in nociception is required to inform management decisions. The greater prevalence of BML observed in symptomatic populations is congruent with recent findings showing the association of such lesions with clinical symptoms and impaired patient-reported outcomes. ${ }^{74581}$ In addition, individuals with acetabular and femoral cartilage defects have a greater prevalence of BML, which may demonstrate an association between such defects and early arthritic change. ${ }^{74}$

Two recent reviews ${ }^{29} 30$ have reported on the prevalence of intra-articular hip pathologies. The review undertaken by Frank et $a l^{30}$ reported a higher prevalence of labral tears in asymptomatic individuals (68\% vs 54\%), which likely reflects the 11 new studies published since the completion of their literature search, and our decision to distinguish the prevalence of pathologies by either person or hip. The review by Mascarenhas $e a^{29}$ reported on labral tears and cartilage defects in symptomatic, asymptomatic and athletic individuals. The prevalence of labral tears in symptomatic individuals was lower than our results $(28 \%$ vs $62 \%)$. The variation in results can be explained through the differences seen in review aims, methods used to combine prevalence figures and the large variation in studies included in each review.

The findings of our review should be interpreted in conjunction with the known limitations of diagnostic imaging. In particular, we highlighted that labral tears were observed on MRI in a high number of asymptomatic individuals (54\%). Magnetic resonance imaging across various field strengths with and without the use of contrast agents has variable diagnostic utility to identify labral pathology, ${ }^{18} 82$ which may result in overestimation or underestimation of prevalence in asymptomatic individuals. However, 4 of the 8 studies included in meta-analysis used $3 \mathrm{~T}$ MRI, which may provide greater accuracy compared with lower field strength systems ${ }^{83}$ and increases confidence in our findings. Contrast-enhanced MRA provides the highest diagnostic accuracy in the identification of labral tears. Unfortunately, no studies including MRA on asymptomatic individuals were identified in this review. Further studies are necessary to determine whether MRA findings of labral tears in asymptomatic individuals agree with the current analysis. The disparity in cartilage defects is a notable result, with this trend observed in studies using MRA and MRI. The use of low-field strength MRA protocols across the studies included in meta-analysis increases the possibility of misinterpretation of cartilage defects in symptomatic individuals. Conversely, a number of studies used $3 \mathrm{~T}$ MRI for analysis of cartilage defects in symptomatics and consistently demonstrated a higher prevalence. As 3 T MRI provides greater visualisation of acetabular and femoral articular cartilage, ${ }^{8384}$ it may be that the prevalence of cartilage defects is indeed higher in symptomatic individuals.

The decision to dichotomise the imaging findings may have resulted in an overestimation of prevalence. However, this method was deemed necessary due to the variability in methods used to grade intra-articular pathology. ${ }^{75} 76$ The recent development of semiquantitative methods for the assessment of hip structural pathologies has shown promise with high levels of reliability and agreement. ${ }^{75}{ }^{76}$ Furthermore, these methods have shown moderate correlation with patient-reported outcome measures. ${ }^{76}$ Future research should focus on developing consensus for the grading of intra-articular pathologies as this will provide a better understanding of the true spectrum of pathology.

In total, 5 of the 29 included studies were adjudged to have HR, highlighting poor study methodology in the current literature evaluating the prevalence of intra-articular hip pathologies. Study populations were often attained by convenience and not deemed representative of a wider population, reducing the generalisability of the reviews findings. The reliability and level of agreement for the diagnostic criteria used to evaluate intra-articular pathologies were often not documented in studies, reducing confidence in the reported findings. The method used to determine prevalence was variable across studies. Prevalence by definition should be determined by dividing 'the number of cases of a disease in a population, by the population number'. ${ }^{85}$ Our decision to adjudge studies reporting prevalence per hip as high risk of bias was in line with recent literature. ${ }^{86}$ Exclusion of HR studies in the meta-analyses may increase confidence in the findings of this review. However, limited to moderate-level evidence was 
assigned with our findings, outlining that studies of greater methodological quality are still required.

The high levels of heterogeneity observed in the pooled symptomatic and asymptomatic populations are akin to other prevalence reviews. ${ }^{24} 87$ In relation to this review, it likely reflects variability in imaging modalities and parameters used across the included studies. Other sources of heterogeneity may include variations in age, sex and levels of physical activity across the included studies. Interestingly, high levels of heterogeneity were present despite the exclusion of HR studies, which may indicate that study quality and heterogeneity are not directly related in this review.

\section{Limitations}

There are a number of limitations relating to the results of this review. First, the decision to exclude studies investigating the prevalence of intra-articular hip pathologies in individuals with slipped capital femoral epiphysis and Legg-Calve-Perthes disease reduces the generalisability of our findings specifically to these conditions. Second, a number of studies were excluded on the basis of not identifying a primary aim of reporting the prevalence of intra-articular hip pathologies. ${ }^{88-91}$ While excluded, the results from the aforementioned studies are very similar to those achieved in our review, providing validation of the results of this review. Third, unpublished studies and those not published in the English language were not included in this review which may have excluded some relevant studies. A notable limitation of the studies in this review is the inclusion of participants based on the presence of hip and/or groin pain. Hip and groin-related pain can be caused by a number of different intra-articular and extra-articular conditions, ${ }^{10} 1314$ hence the relevance of imaging-defined intra-articular pathologies may be questionable in some symptomatic individuals.

Importantly, the studies in this review evaluate highly selective populations, meaning the results of this review are not interpretable beyond the inclusion criteria of the included studies. Furthermore, there is limited comparability between the included studies which further reduces the generalisability of the reviews findings. Consideration is needed regarding the use of the term 'prevalence' to describe the findings of this review as none of the included studies evaluated community-based populations. Finally, the intra-articular pathologies identified with imaging in both symptomatic and asymptomatic individuals were not confirmed by hip arthroscopy, which is currently considered the gold standard for diagnosis of intra-articular hip pathologies. Although this is a notable limitation, arthroscopic confirmation of intra-articular pathologies will never be a consideration in asymptomatic populations.

\section{CONCLUSION}

This systematic review identified 29 studies. The included studies used MRI, MRA and CT to investigate the prevalence of intra-articular hip pathologies. Most studies had a moderate to high risk of bias with only five low-risk studies. The prevalence of cartilage pathology is higher in people with pain than those without. In contrast, the prevalence of labral pathology is similar in those with and without pain. Bone marrow lesions and ligamentum teres tears appear to be more prevalent in individuals with pain. Paralabral cysts and herniation pits are prevalent in both symptomatic and asymptomatic individuals. This review highlights the uncertainty of the relationship between intra-articular hip joint pathology on imaging and pain. A greater understanding of this relationship may improve the selection and effectiveness
What is already known?

- Diagnostic imaging is used to evaluate the cause of symptoms in individuals with hip, groin or buttock pain.

- Intra-articular hip pathologies found on imaging are often a catalyst for surgical interventions in those with hip, groin or buttock pain.

- The prevalence of pathological findings has been shown to be high in those with and without pain in other anatomical regions.

\section{What are the new findings?}

- Labral tear prevalence is high in those with and without hip, groin or buttock pain.

- Cartilage defects are seen more often in individuals with pain.

- Bone marrow lesions and ligamentum teres tears are more prevalent in individuals with pain.

- Herniation pits and paralabral cysts are seen at similar rates in individuals with and without pain.

- Uncertainty surrounds the relationship between imagingdefined intra-articular pathology and pain.

- Studies evaluating true community-based populations are needed to better understand the true prevalence of intraarticular hip pathologies in asymptomatic and symptomatic individuals.

of conservative and surgical interventions for intra-articular hip pathologies.

Contributors JJH, JLK and KMC were responsible for the creation and planning of the review. JJH and JLK were responsible for the search strategy used. JJH, JLK and DMJ developed the strategy to evaluate study quality. JJH, ABM and KMC were involved in the data extraction process. JJH wrote the final manuscript with all authors assisting in revising content.

Competing interests None declared.

Provenance and peer review Not commissioned; externally peer reviewed

(c) Article author(s) (or their employer(s) unless otherwise stated in the text of the article) 2018. All rights reserved. No commercial use is permitted unless otherwise expressly granted.

\section{REFERENCES}

1 Thorborg K, Rathleff MS, Petersen P, et al. Prevalence and severity of hip and groin pain in sub-elite male football: a cross-sectional cohort study of 695 players. Scand J Med Sci Sports 2017;27:107-14

2 Kemp JL, Makdissi M, Schache AG, et al. Hip chondropathy at arthroscopy: prevalence and relationship to labral pathology, femoroacetabular impingement and patientreported outcomes. Br J Sports Med 2014;48:1102-7.

3 Picavet HS, Schouten JS. Musculoskeletal pain in the Netherlands: prevalences, consequences and risk groups, the DMC(3)-study. Pain 2003;102:167-78.

4 Hölmich P, Thorborg K, Dehlendorff C, et al. Incidence and clinical presentation of groin injuries in sub-elite male soccer. Br J Sports Med 2014;48:1245-50.

5 Dawson J, Linsell L, Zondervan $\mathrm{K}$, et al. Epidemiology of hip and knee pain and its impact on overall health status in older adults. Rheumatology (Oxford) 2004;43:497-504.

6 Vullo VJ, Richardson JK, Hurvitz EA. Hip, knee, and foot pain during pregnancy and the postpartum period. J Fam Pract 1996:43:63-8.

7 Nevin F, Delahunt E. Adductor squeeze test values and hip joint range of motion in Gaelic football athletes with longstanding groin pain. J Sci Med Sport 2014;17:155-9.

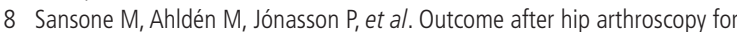
femoroacetabular impingement in 289 patients with minimum 2-year follow-up. Scand J Med Sci Sports 2017;27:230-5. 
9 Filbay SR, Kemp JL, Ackerman IN, et al. Quality of life impairments after hip arthroscopy in people with hip chondropathy. J Hip Preserv Surg 2016;3:154-64.

10 Reiman MP, Thorborg K. Clinical examination and physical assessment of hip jointrelated pain in athletes. Int J Sports Phys Ther 2014;9:737-55.

11 Meyers WC, Foley DP, Garrett WE, et al. Management of severe lower abdominal or inguinal pain in high-performance athletes. PAIN (Performing Athletes with Abdominal or Inguinal Neuromuscular Pain Study Group). Am J Sports Med 2000;28:2-8.

12 Anderson K, Strickland SM, Warren R. Hip and groin injuries in athletes. Am J Sports Med 2001;29:521-33.

13 Weir A, Brukner P, Delahunt E, et al. Doha agreement meeting on terminology and definitions in groin pain in athletes. Br J Sports Med 2015;49:768-74.

14 Hölmich P. Long-standing groin pain in sportspeople falls into three primary patterns, a "clinical entity" approach: a prospective study of 207 patients. Br J Sports Med 2007:41:247-52.

15 Smith TO, Hilton G, Toms AP, et al. The diagnostic accuracy of acetabular labral tears using magnetic resonance imaging and magnetic resonance arthrography: a metaanalysis. Eur Radiol 2011;21:863-74

16 Bencardino JT, Kassarjian A, Palmer WE. Magnetic resonance imaging of the hip: sports-related injuries. Top Magn Reson Imaging 2003;14:145-60.

17 Reiman MP, Mather RC, Hash TW, et al. Examination of acetabular labral tear: a continued diagnostic challenge. Br J Sports Med 2014;48:311-9.

18 Naraghi A, White LM. MRI of labral and chondral lesions of the hip. AJR Am J Roentgenol 2015;205:479-90.

19 Sing DC, Feeley BT, Tay B, et al. Age-related trends in hip arthroscopy: a large crosssectional analysis. Arthroscopy 2015;31:2307-13.

20 Montgomery SR, Ngo SS, Hobson T, et al. Trends and demographics in hip arthroscopy in the United States. Arthroscopy 2013:29:661-5.

21 Matsumoto M, Okada E, Ichihara D, et al. Age-related changes of thoracic and cervical intervertebral discs in asymptomatic subjects. Spine (Phila Pa 1976) 2010;35:1359-64.

22 Wood KB, Garvey TA, Gundry C, et al. Magnetic resonance imaging of the thoracic spine. Evaluation of asymptomatic individuals. J Bone Joint Surg Am 1995;77:1631-8.

23 Guermazi A, Niu J, Hayashi D, et al. Prevalence of abnormalities in knees detected by MRI in adults without knee osteoarthritis: population based observational study (Framingham Osteoarthritis Study). BMJ 2012;345:e5339.

24 Pereira $D$, Peleteiro B, Araújo J, et al. The effect of osteoarthritis definition on prevalence and incidence estimates: a systematic review. Osteoarthritis Cartilage 2011:19:1270-85.

25 Teunis T, Lubberts B, Reilly BT, et al. A systematic review and pooled analysis of the prevalence of rotator cuff disease with increasing age. J Shoulder Elbow Surg 2014;23:1913-21.

26 Sutter R, Zanetti M, Pfirrmann CW. New developments in hip imaging. Radiology 2012;264:651-67.

27 Peters S, Laing A, Emerson C, et al. Surgical criteria for femoroacetabular impingement syndrome: a scoping review. Br J Sports Med 2017:51:1605-10.

28 Kwee RM, Kavanagh EC, Adriaensen ME. Normal anatomical variants of the labrum of the hip at magnetic resonance imaging: a systematic review. Eur Radiol 2013;23:1694-710.

29 Mascarenhas VV, Rego P, Dantas P, et al. Imaging prevalence of femoroacetabular impingement in symptomatic patients, athletes, and asymptomatic individuals: a systematic review. Eur J Radiol 2016;85:73-95.

30 Frank JM, Harris JD, Erickson BJ, et al. Prevalence of femoroacetabular impingement imaging findings in asymptomatic volunteers: a systematic review. Arthroscopy 2015:31:1199-204.

31 Hoy D, Brooks $P$, Woolf A, et al. Assessing risk of bias in prevalence studies: modification of an existing tool and evidence of interrater agreement. J Clin Epidemiol 2012;65:934-9

32 Taylor JB, Goode AP, George SZ, et al. Incidence and risk factors for first-time incident low back pain: a systematic review and meta-analysis. Spine J 2014;14:2299-319.

33 Landis JR, Koch GG. The measurement of observer agreement for categorical data. Biometrics 1977;33:159-74.

34 Higgins J, Green S. Cochrane Handbook for Systematic Reviews of Interventions Version 5.1.0: The Cochrane Collaboration. 2011.

35 Weir A, Rabia S, Ardern C. Trusting systematic reviews and meta-analyses: all that glitters is not gold!. Br J Sports Med 2016;50:1100-1.

36 Higgins JP, Thompson SG, Deeks JJ, et al. Measuring inconsistency in meta-analyses. BMJ 2003:327:557-60.

37 van Tulder M, Furlan A, Bombardier C, et al. Updated method guidelines for systematic reviews in the cochrane collaboration back review group. Spine 2003;28:1290-9.

38 Rathleff MS, Rathleff CR, Crossley KM, et al. Is hip strength a risk factor for patellofemoral pain? A systematic review and meta-analysis. Br J Sports Med 2014;48:1088

39 Liberati A, Altman DG, Tetzlaff J, et al. The PRISMA statement for reporting systematic reviews and meta-analyses of studies that evaluate health care interventions: explanation and elaboration. PLoS Med 2009;6:e1000100.

40 Ayeni OR, Banga K, Bhandari M, et al. Femoroacetabular impingement in elite ice hockey players. Knee Surg Sports Traumatol Arthrosc 2014;22:920-5.
41 Kassarjian A, Yoon LS, Belzile E, et al. Triad of MR arthrographic findings in patients with cam-type femoroacetabular impingement. Radiology 2005;236:588-92.

42 Lahner M, Walter PA, von Schulze Pellengahr C, et al. Comparative study of the femoroacetabular impingement (FAI) prevalence in male semiprofessional and amateur soccer players. Arch Orthop Trauma Surg 2014;134:1135-41.

43 Mayes $S$, Ferris AR, Smith $P$, et al. Atraumatic tears of the ligamentum teres are more frequent in professional ballet dancers than a sporting population. Skeletal Radiol 2016:45:959-67.

44 Narvani AA, Tsiridis E, Kendall S, et al. A preliminary report on prevalence of acetabular labrum tears in sports patients with groin pain. Knee Surg Sports Traumatol Arthrosc 2003:11:403-8.

45 Neumann G, Mendicuti AD, Zou KH, et al. Prevalence of labral tears and cartilage loss in patients with mechanical symptoms of the hip: evaluation using MR arthrography. Osteoarthritis Cartilage 2007;15:909-17.

46 Panzer S, Augat P, Esch U. CT assessment of herniation pits: prevalence, characteristics, and potential association with morphological predictors of femoroacetabular impingement. Eur Radiol 2008;18:1869-75.

47 Pizzolatti ALA, Haupenthal A, Marostika A, et al. Magnetic resonance arthrographic findings in subjects with acetabular labral tears. Acta Ortop Bras 2011;19:22-7.

48 Silvis ML, Mosher TJ, Smetana BS, et al. High prevalence of pelvic and hip magnetic resonance imaging findings in asymptomatic collegiate and professional hockey players. Am J Sports Med 2011;39:715-21.

49 Register B, Pennock AT, Ho CP, et al. Prevalence of abnormal hip findings in asymptomatic participants: a prospective, blinded study. Am J Sports Med 2012;40:2720-4

50 Schmitz MR, Campbell SE, Fajardo RS, et al. Identification of acetabular labra pathological changes in asymptomatic volunteers using optimized, noncontrast 1.5-T magnetic resonance imaging. Am J Sports Med 2012:40:1337-41.

51 Kolo FC, Charbonnier C, Pfirrmann CW, et al. Extreme hip motion in professional ballet dancers: dynamic and morphological evaluation based on magnetic resonance imaging. Skeletal Radiol 2013;42:689-98.

52 Leunig $M$, Jüni P, Werlen $S$, et al. Prevalence of cam and pincer-type deformities on hip MRI in an asymptomatic young Swiss female population: a cross-sectional study. Osteoarthritis Cartilage 2013;21:544-50.

53 Philippon MJ, Ho CP, Briggs KK, et al. Prevalence of increased alpha angles as a measure of cam-type femoroacetabular impingement in youth ice hockey players. Am J Sports Med 2013:41:1357-62.

54 Yuan BJ, Bartelt RB, Levy BA, et al. Decreased range of motion is associated with structural hip deformity in asymptomatic adolescent athletes. Am J Sports Med 2013:41:1519-25.

55 Domb BG, Jackson TJ, Carter CC, et al. Magnetic resonance imaging findings in the symptomatic hips of younger retired national football league players. Am J Sports Med 2014;42:1704-9.

$56 \mathrm{Ji} \mathrm{HM}$, Baek JH, Kim KW, et al. Herniation pits as a radiographic indicator of pincertype femoroacetabular impingement in symptomatic patients. Knee Surg Sports Traumatol Arthrosc 2014:22:860-6.

57 Lahner M, Bader S, Walter PA, et al. Prevalence of femoro-acetabular impingement in international competitive track and field athletes. Int Orthop 2014:38:2571-6.

58 Mayes S, Ferris AR, Smith P, et al. Similar prevalence of acetabular labral tear in professional ballet dancers and sporting participants. Clin J Sport Med 2016;26:307-13.

59 Farrell G, McGrath F, Hogan B, et al. 95\% prevalence of abnormality on hip MRI in elite academy level rugby union: a clinical and imaging study of hip disorders. J Sci Med Sport 2016;19:893-7.

60 Georgiadis AG, Seeley MA, Chauvin NA, et al. Prevalence of acetabular labral tears in asymptomatic children. J Child Orthop 2016;10:149-54

61 Jayakar R, Merz A, Plotkin B, et al. Magnetic resonance arthrography and the prevalence of acetabular labral tears in patients 50 years of age and older. Skeletal Radiol 2016:45:1061-7.

62 Mineta K, Goto T, Wada K, et al. Comparison of femoroacetabular impingementrelated radiographic features in a convenience sample of Japanese patients with and without herniation pits. Skeletal Radiol 2016;45:1079-88.

63 Neiman M, Halshtok Neiman 0, Aharoni D, et al. Magnetic resonance arthrography of the hip: prevalence of diagnoses not suspected by the referring physician and correlation with clinical examination and pain score. Acta Radiol 2016:57:595-601.

64 Lee AJ, Armour P, Thind D, et al. The prevalence of acetabular labral tears and associated pathology in a young asymptomatic population. Bone Joint J 2015;97B:623-7.

65 Mayes S, Ferris AR, Smith $\mathrm{P}$, et al. Professional ballet dancers have a similar prevalence of articular cartilage defects compared to age- and sex-matched non-dancing athletes. Clin Rheumatol 2016:35:3037-43.

66 Tresch F, Dietrich TJ, Pfirrmann CWA, et al. Hip MRI: prevalence of articular cartilage defects and labral tears in asymptomatic volunteers. A comparison with a matched population of patients with femoroacetabular impingement. J Magn Reson Imaging 2017;46:440-51

67 Dickenson $\mathrm{E}, \mathrm{O}^{\prime}$ Connor $\mathrm{P}$, Robinson $\mathrm{P}$, et al. Hip morphology in elite golfers: asymmetry between lead and trail hips. Br J Sports Med 2016;50:1081-6. 
68 Teichtahl AJ, Wang Y, Smith S, et al. Structural changes of hip osteoarthritis using magnetic resonance imaging. Arthritis Res Ther 2014;16:466.

69 Kim C, Nevitt MC, Niu J, et al. Association of hip pain with radiographic evidence of hip osteoarthritis: diagnostic test study. BMJ 2015;351:h5983.

70 Alzaharani A, Bali K, Gudena R, et al. The innervation of the human acetabular labrum and hip joint: an anatomic study. BMC Musculoskelet Disord 2014;15:41

71 Gerhardt M, Johnson K, Atkinson R, et al. Characterisation and classification of the neural anatomy in the human hip joint. Hip Int 2012;22:75-81.

72 Bsat S, Frei H, Beaulé PE. The acetabular labrum: a review of its function. Bone Joint $J$ 2016:98-B:730-5.

73 Lewis CL, Sahrmann SA. Acetabular labral tears. Phys Ther 2006;86:110-21.

74 Kumar D, Wyatt CR, Lee S, et al. Association of cartilage defects, and other MRI findings with pain and function in individuals with mild-moderate radiographic hip osteoarthritis and controls. Osteoarthritis Cartilage 2013;21:1685-92.

75 Roemer FW, Hunter DJ, Winterstein A, et al. Hip Osteoarthritis MRI Scoring System (HOAMS): reliability and associations with radiographic and clinical findings. Osteoarthritis Cartilage 2011;19:946-62.

76 Lee S, Nardo L, Kumar D, et al. Scoring hip osteoarthritis with MRI (SHOMRI): a whole joint osteoarthritis evaluation system. J Magn Reson Imaging 2015;41:1549-57.

77 Susko AM, Fitzgerald GK. The pain-relieving qualities of exercise in knee osteoarthritis. Open Access Rheumatol 2013;5:81-91.

78 Lluch Girbés E, Nijs J, Torres-Cueco R, et al. Pain treatment for patients with osteoarthritis and central sensitization. Phys Ther 2013;93:842-51.

79 Creamer P. Osteoarthritis pain and its treatment. Curr Opin Rheumatol 2000;12:450-5

80 Haversath $\mathrm{M}$, Hanke J, Landgraeber S, et al. The distribution of nociceptive innervation in the painful hip: a histological investigation. Bone Joint J 2013;95-B:770-6.

81 Schwaiger BJ, Gersing AS, Lee S, et al. Longitudinal assessment of MRI in hip osteoarthritis using SHOMRI and correlation with clinical progression. Semin Arthritis Rheum 2016;45:648-55.
82 Reiman MP, Thorborg K, Goode AP, et al. Diagnostic accuracy of imaging modalities and injection techniques for the diagnosis of femoroacetabular impingement/labral tear: a systematic review with meta-analysis. Am J Sports Med 2017:45:2665-77.

83 Linda DD, Naraghi A, Murnaghan L, et al. Accuracy of non-arthrographic 3T MR imaging in evaluation of intra-articular pathology of the hip in femoroacetabular impingement. Skeletal Radiol 2017;46:299-308.

84 Schleich C, Hesper T, Hosalkar HS, et al. 3D double-echo steady-state sequence assessment of hip joint cartilage and labrum at 3 Tesla: comparative analysis of magnetic resonance imaging and intraoperative data. Eur Radiol 2017:27:4360-71.

85 Barendregt JJ, Doi SA, Lee YY, et al. Meta-analysis of prevalence. J Epidemiol Community Health 2013;67:974-8.

86 Dickenson E, Wall PD, Robinson B, et al. Prevalence of cam hip shape morphology: a systematic review. Osteoarthritis Cartilage 2016;24:949-61.

87 Kobayashi S, Pappas E, Fransen M, et al. The prevalence of patellofemoral osteoarthritis: a systematic review and meta-analysis. Osteoarthritis Cartilage 2016;24:1697-707.

88 Abe I, Harada Y, Oinuma K, et al. Acetabular labrum: abnormal findings at MR imaging in asymptomatic hips. Radiology 2000;216:576-81.

89 Bellaïche L, Lequesne M, Gedouin JE, et al. Imaging data in a prospective series of adult hip pain in under-50 year-olds. Orthop Traumatol Surg Res 2010;96:S44-52.

90 Kassarjian A, Llopis E, Schwartz RB, et al. Obturator externus bursa: prevalence of communication with the hip joint and associated intra-articular findings in 200 consecutive hip MR arthrograms. Eur Radiol 2009;19:2779-82.

91 Aydingöz U, Oztürk MH. MR imaging of the acetabular labrum: a comparative study of both hips in 180 asymptomatic volunteers. Eur Radiol 2001;11:567-74. 